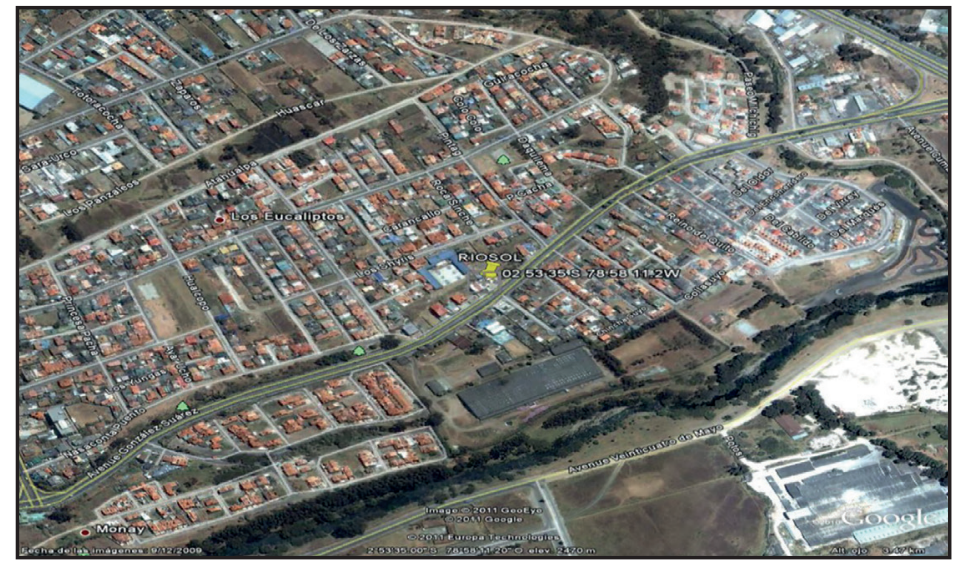

\title{
PARTICIPACIÓN Y VEEDURÍA CIUDADANA EN LA APROBACIÓN DE INSTRUMENTOS PARA LA EVALUACIÓN DE LA GESTIÓN AMBIENTAL EN EL CANTÓN CUENCA

\author{
Bucheli García, Franklin
}

Correspondencia: franklinb@uazuay.edu.ec 


\section{Resumen}

Los procesos de participación y veeduría social como componentes de la legislación y la gestión ambiental en el Ecuador son relativamente nuevos, se definen primero como principio en las Políticas Básicas Ambientales del año 19941, luego como un derecho en la Ley de Gestión Ambiental de 1999, en la que se determina que "Toda persona natural o jurídica tiene derecho a participar en la gestión ambiental, a través de los mecanismos que para el efecto establezca el reglamento. Las personas tienen derecho a ser informadas oportuna y suficientemente sobre cualquier actividad de las instituciones del Estado que puedan producir impactos ambientales". ${ }^{2}$

Con este precedente, la instrumentación efectiva de estos procesos se consolida en el año 2003 con la expedición de la Legislación Ambiental Secundaria del Ministerio del Ambiente ${ }^{3}$, que establece que la participación social en la gestión ambiental se rige por los principios de legitimidad y representatividad, constituyendo un esfuerzo tripartito del Estado la ciudadanía y el promotor interesado en realizar una actividad o proyecto. A esta fecha la única instancia administrativa para la coordinación y desarrollo de la participación ciudadana es la autoridad ambiental nacional.

Políticas Básicas Ambientales del Ecuador CAAM 1994.

Codificación de la Ley de Gestión Ambiental del Ecuador. R.

O. No. 418 de 10-09-2004.

3 Texto Unificado de Legislación Secundaria del Ministerio del Ambiente. Decreto No. 3399 R.O. 2 de 31-III-2003. 
Las autoridades ambientales locales de aplicación responsable (gobiernos autónomos descentralizados provinciales y municipales) inician la aplicación de los procesos de participación y veeduría social como elemento de la gestión ambiental a partir de mayo del 2008, con la promulgación del Decreto Ejecutivo $1040^{4}$.

Por lo mismo los proyectos de infraestructura, servicios y desarrollo de actividades productivas en el cantón Cuenca, que puedan afectar al ambiente, previamente a su ejecución deben contar obligatoriamente con los criterios de la comunidad, según lo dispone la Ordenanza del Subsistema de Evaluación de Impacto Ambiental.

Por lo expuesto es importante monitorear y evaluar el cumplimiento del principio de participación social, por parte, tanto de la autoridad ambiental local (Comisión de Gestión Ambiental) ${ }^{5}$, como por los promotores (regulados) y la ciudadanía, para de esta manera establecer su eficiencia y efectividad como elemento fundamental del derecho y la gestión ambiental, así como su aporte a la calidad ambiental y de vida en el cantón Cuenca.

Palabras clave: Participación social, monitoreo ambiental, Veeduría ciudadana, gobierno local, aprobación de instrumentos de evaluación ambiental.

4 Reglamento de Aplicación de Mecanismos de Participación Social establecidos en la Ley de Gestión Ambiental. R. O. 8-05-2012.

5 Comisión de Gestión Ambiental de Cuenca, Autoridad Ambiental de Aplicación Responsable. 2005. 


\section{SUMMARY}

The processes of social participation and supervision as components of legislation and environmental management in Ecuador are relatively new, are first defined as a principle in Environmental Basic Policy of 1994, then as a right in the Environmental Management Act 1999 in which states that "Every natural or legal person is entitled to participate in environmental management, through the mechanisms for the purpose by the rules. People have a right to be informed promptly and sufficiently on any activity State institutions that produce environmental impacts".

With this precedent, the effective implementation of these processes are consolidated in 2003 with the issuance of the Secondary Environmental Legislation of the Ministry of Environment, which states that social participation in environmental management is guided by the principles of legitimacy and representativeness, constituting a tripartite effort of the state, citizenship, and the promoter interested in doing an activity or project, to this date the only administrative body for the coordination and development of citizen participation is the national environmental authority.

Localenvironmentalauthorities responsibleenforcement (provincial and municipal decentralize governments) start implementing participatory processes and social oversight as part of the environmental management from May 2008, with the promulgation of Executive Order 1040.

Therefore infrastructure projects, services and productive activities in the canton Cuenca, which may 
affect the environment, prior to its execution must have compulsorily to the criteria of the community, as provided by Subsystem of Environmental Evaluation Impact Ordinance.

For these reasons it is important to monitor and evaluate the implementation of the principle of social participation, both by the local environmental authority (Environmental Management Commission), by promoters (regulated) and citizenship, to thereby establish its efficiency and effectiveness as a key element of the environmental management and Law, as well as its contribution to environmental quality and living in the canton Cuenca.

Keywords: Social participation, environmental monitoring, citizen accompaniment, local government, approval of environmental assessment instruments. 


\section{INTRODUCCIÓN}

La finalidad sustancial de la participación social en la gestión ambiental es considerar e incorporar los criterios y observaciones, especialmente de la población directamente afectada por el desarrollo de una obra o proyecto; pero lamentablemente la sociedad no se encuentra suficientemente capacitada e informada, lo que hace que estos espacios no cumplan los objetivos para los cuales fueron establecidos.

La participación y veeduría social en materia ambiental debe superar una serie de inconvenientes como son la falta de información, difusión, e involucramiento, pues los mecanismos establecidos para el efecto deben ser mejorados sustancialmente, dado que es evidente una muy poca participación de la ciudadanía en la gestión ambiental local.

La participación ciudadana en unos casos no existe, por la falta de mecanismos adecuados que permitan difundir adecuadamente los proyectos e incentivar la participación; en otros casos cuando se da no es efectiva, es decir no permite recoger las observaciones de la población respecto de una obra o proyecto por la falta de capacitación en materia ambiental; en el mejor de los casos se da a conocer el contenido del instrumento de evaluación ambiental (ficha ambiental, estudio de impacto ambiental, auditoría ambiental) y nada más.

Los mecanismos de participación social reconocidos son insuficientes, lo que incide en la falta de una 
participación de calidad y en cantidad suficiente que garantice una efectiva toma de decisiones por parte de la autoridad ambiental respecto de obras, proyectos o servicios puestos a su consideración.

El principio constitucional (Art. 395 literal 3$)^{6}$ establece que el protagonista de la gestión ambiental es la ciudadanía, debido a que en cualquier instancia puede intervenir cuando un proyecto u obra cause impactos ambientales que la perjudiquen. En función de este principio se entiende que la participación es totalmente abierta sin más restricciones que las establecidas por la misma ley, sin embargo las disposiciones normativas secundarias (Reglamentos, Acuerdos Ministeriales y Ordenanzas) sobre estos procesos limitan la participación a ciertas actividades, proyectos o servicios, dependiendo de la categorización, establecidas por la autoridad ambiental local, asimismo se restringe la participación a etapas y momentos exclusivos. Las convocatorias no siempre son eficaces y por ende la participación es escasa; las observaciones sustanciales producto de la participación social no son necesariamente consideradas por los promotores e incluidas en los estudios y planes de manejo por parte de los consultores para su cumplimiento, lo que genera desconfianza e inseguridad en la población.

La falta de una organización de base adecuada por parte de la ciudadanía es un problema, a pesar de no ser requisito para la participación la organización social, pero si es necesaria para obtener mejores resultados de estos procesos, pues muchas veces se pretende que prevalezcan intereses particulares antes que los de la comunidad.

6 Constitución de la República del Ecuador. 2008 
Otro asunto a considerar en estos procesos es la intromisión política para obtener un resultado que favorezca a un proyecto de su interés. Esto que comenzó como una preocupación actualmente es una realidad y se ha convertido en parte de la problemática ambiental, pues en muchos casos se termina cediendo a la presión de los organismos de gobierno.

Por lo expuesto debe estar claro que la participación y veeduría social son un proceso dentro de la gestión ambiental, que contribuye de manera técnica, legal y social a mejorar los procesos productivos, de infraestructura, y servicios para el buen vivir, principalmente de la población local, por lo que requiere ser monitoreado permanentemente para determinar su verdadera contribución al mejoramiento de la calidad de vida y del ambiente.

Todo esto con la finalidad de contribuir a contar con un sistema que permita monitorear la participación ciudadana en el cantón Cuenca, en los procedimientos desarrollados por la autoridad ambiental local para la aprobación de instrumentos de evaluación de la gestión ambiental, y de esta manera evaluar el ejercicio y el rol de la veeduría ciudadanía en la gestión ambiental.

\section{CAPÍTULO I}

\section{MARCO TEÓRICO}

\subsection{CONCEPTUALIZACIÓN}

El ejercicio del derecho de la gente a vivir en un ambiente sano, ecológicamente equilibrado y libre de 
contaminación, así como el cumplimiento del deber de preservar el ambiente en sus condiciones naturales, implica un involucramiento ciudadano directo, dado que se trata del mayor patrimonio y bien público con el que cuenta la humanidad para su desarrollo, por lo mismo la única forma de defenderlo y conservarlo es con la participación activa de toda la población.

De manera equivocada los organismos de gobierno han considerado que es una acción privativa del sector público desarrollar acciones de preservación del ambiente, toda vez que este lo constituyen los recursos naturales que forman parte del patrimonio del Estado, cuando en realidad es responsabilidad de toda la sociedad (sector público como privado) su conservación, puesto que cualquier intervención sobre el ambiente directamente beneficia o perjudica a todos. esto es evidente cuando se desarrollan actividades productivas, infraestructura 0 se prestan servicios de cualquier naturaleza, estos sí autorizados exclusivamente por el sector público, muchas de las veces sin el conocimiento, peor aún con la participación ciudadana.

Por ello es necesario generar una cultura ambiental en la ciudadanía, a fin de que esta conozca y aplique adecuadamente los mecanismos de participación y veeduría ambiental en función de ejercer eficiente y efectivamente la corresponsabilidad que en esta materia le corresponde.

Según nuestra Constitución y la norma ambiental del país, el protagonista en la gestión ambiental es la ciudadanía, pero estas disposiciones no sirven de mucho porque la población no cuenta con el suficiente conocimiento para ser parte de la misma, de ahí la importancia no solamente de 
contar con la información sino además con la capacitación necesaria para realizar una responsable participación ciudadana en relación con el ambiente.

Autoridad ambiental. Institución pública que ejerce la competencia en materia ambiental, sobre determinados recursos, a nivel nacional, regional y seccional.

Control ambiental. Proceso técnico de carácter fiscalizador, realizado por la autoridad ambiental, o comunidad durante la implementación y ejecución de un proyecto o actividad, para establecer el cumplimiento del plan de manejo ambiental.

Estudio de impacto ambiental. Documento técnico que debe presentar el titular del proyecto, obra o actividad que va a ser sometido al procedimiento de evaluación de impacto ambiental. Establece la predicción e identificación de los impactos ambientales, describe las medidas para prevenir, controlar, mitigar y compensar las alteraciones ambientales significativas.

Licencia ambiental. Documento necesario y obligatorio, otorgado por la autoridad ambiental, para que el promotor pueda ejecutar la respectiva actividad, obra o proyecto de acuerdo con el estudio de impacto ambiental aprobado.

Lista taxativa. Determinación por parte de la autoridad ambiental de la categorización de actividades productivas, para el sometimiento del trámite de evaluación ambiental.

Veeduría ciudadana. Según el Consejo de Participación Ciudadana y Control Social ${ }^{7}$, las veedurías ciudadanas

7 Entidad integrante de la Función de Transparencia y Control, 134 
"son mecanismos de participación y control social, mediante los cuales los ciudadanos y ciudadanas ejercen el derecho constitucional de controlar, de manera objetiva e imparcial, la administración y gestión de lo público". De lo anotado se desprende que el propósito de la veeduría es la intervención de la ciudadanía en general en el manejo de la gestión y administración de lo público, que en principio se regula como medida preventiva de actos de corrupción.

De lo anotado se desprende que el ejercicio del control socio-ambiental se lo puede hacer a todas las entidades del sector público en todos los niveles de gobierno (nacional, regional, provincial, cantonal y parroquial) que formen parte del Sistema Nacional de Gestión Ambiental Descentralizada $^{8}$. Esto incluye las políticas, planes, proyectos, programas, procesos, obras y servicios públicos; las actuaciones de los servidores públicos en general; a las personas naturales o jurídicas del sector privado que presten servicios públicos, manejen recursos públicos 0 desarrollen actividades de interés público.

Bajo esta caracterización, las atribuciones que vienen cumpliendo las veedurías ciudadanas ambientales en el cantón Cuenca son las siguientes:

a. Solicitar información o los documentos necesarios para el desempeño de su actividad a cualquier funcionario público o persona natural o jurídica que tuviera vinculación con el objeto de la veeduría, así como a interventores, autoridades contratantes y a aquellas

determinada en la Constitución de la República de 2008. Su función es promover el ejercicio de los derechos de participación y control social de lo público.

8 Establecido con la promulgación de la Ley de Gestión Ambiental en el año 1999. 
personas que tuvieran alguna vinculación con el cumplimiento de los respectivos programas, contratos o proyectos.

b. Ejercer su función en todas las entidades públicas de cualquier nivel o sector de la administración y sobre particulares que tengan vínculo con el sector ambiental en la ejecución de un plan, programa, proyecto o contrato de índole ambiental.

c. Vigilar los procesos de planeación, presupuesto y ejecución del gasto público para el sector ambiental, conocer los planes, proyectos, programas, contratos, recursos presupuestarios asignados, metas fiscales y financieras, procedimientos técnicos y administrativos y los cronogramas de ejecución previstos para los mismos, desde el momento de su iniciación.

d. Evaluar las obras físicas, actividades y los servicios públicos con los impactos o afectación al ambiente y su incidencia en la calidad de vida.

e. Aportar con sus conocimientos, experiencias y criterios para el correcto desarrollo del proceso, plan, programa, etc. objeto de la veeduría.

f. Realizar el acompañamiento, seguimiento y vigilancia del proceso, proyecto, programa, política antes durante y después de su aplicación.

g. Informar a las autoridades competentes sobre las actuaciones, hechos y omisiones de los servidores públicos y de los participantes que ejerzan funciones públicas, que configuren posibles delitos, contravenciones, irregularidades o faltas en materia ambiental.

Para la conformación y desarrollo efectivo y eficiente de la veeduría ciudadana ambiental es necesario seguir un proceso que necesariamente debe considerar las 


\section{siguientes etapas con sus respectivas acciones, siendo de responsabilidad del Comité de Veeduría Social su cumplimiento:}

\begin{tabular}{|c|c|}
\hline ETAPA & ACCIÓN \\
\hline $\begin{array}{l}\text { Información, } \\
\text { empoderamiento y } \\
\text { capacitación. }\end{array}$ & $\begin{array}{l}\text { Es necesario que la población se encuentre } \\
\text { debidamente informada del proceso de evaluación } \\
\text { ambiental que se va a dar seguimiento, debe } \\
\text { también integrarse a dicho proceso al punto de } \\
\text { empoderarse no solamente del mismo sino de la } \\
\text { norma que lo rige, y por último permanentemente } \\
\text { debe estar actualizándose sobre aspectos } \\
\text { relacionados con políticas, regulación y tecnología } \\
\text { ambiental. }\end{array}$ \\
\hline $\begin{array}{l}\text { Identificación del objeto de } \\
\text { la veeduría y determinación } \\
\text { del plazo de ejecución. }\end{array}$ & $\begin{array}{l}\text { Es preciso determinar sobre qué instrumento de } \\
\text { evaluación ambiental se va a realizar la veeduría, } \\
\text { así como el tiempo que debe durar la misma. }\end{array}$ \\
\hline $\begin{array}{l}\text { Elaboración del plan de } \\
\text { veeduría. }\end{array}$ & $\begin{array}{l}\text { Consiste en establecer las acciones, el } \\
\text { cronograma, los responsables y las estrategias a } \\
\text { ser aplicadas durante el desarrollo de la veeduría. }\end{array}$ \\
\hline $\begin{array}{l}\text { Organización y } \\
\text { formalización de la } \\
\text { veeduría. }\end{array}$ & $\begin{array}{l}\text { Son los procedimientos mediante los cuales se } \\
\text { busca la integración y participación ciudadana } \\
\text { dentro del proceso de veeduría, además se } \\
\text { notifica a la autoridad competente sobre la } \\
\text { conformación de la misma. }\end{array}$ \\
\hline $\begin{array}{l}\text { Acercamiento con las } \\
\text { autoridades, personas o } \\
\text { instituciones que serán } \\
\text { objeto de la veeduría } \\
\text { para el establecimiento } \\
\text { de acuerdos en relación } \\
\text { a su participación, } \\
\text { entrega de información } \\
\text { e implementación de las } \\
\text { recomendaciones. }\end{array}$ & $\begin{array}{l}\text { Interacción necesaria con actores institucionales y } \\
\text { sociales relacionados con el proceso de veeduría. }\end{array}$ \\
\hline Ejecución de la Veeduría. & Cumplimiento del plan de veeduría establecido. \\
\hline Socialización de resultados. & $\begin{array}{l}\text { Difusión por todos los medios posibles a la } \\
\text { colectividad de los resultados alcanzados dentro } \\
\text { del proceso de veeduría. }\end{array}$ \\
\hline $\begin{array}{l}\text { Seguimiento de los } \\
\text { resultados. }\end{array}$ & $\begin{array}{l}\text { Monitoreo de los resultados alcanzados para } \\
\text { determinar su cumplimiento }\end{array}$ \\
\hline
\end{tabular}

Elaboración: Franklin Bucheli García. Agosto-2016. 


\subsection{ANTECEDENTES}

La participación social en América Latina en general $y$ en el Ecuador en particular, no es nueva, siempre ha estado presente como parte activa del desarrollo de los pueblos. Varias de estas manifestaciones se han reflejado mediante paros, huelgas, movilizaciones de movimientos indígenas, trabajadores, estudiantes, por mencionar algunos Este tipo de participación la podemos denominar funcional, dado que buscan alcanzar principalmente conquistas sociales.

Con la vigencia de la nueva Constitución del Ecuador en el año $2008^{9}$, esta participación se vuelve más orgánica, y es el resultado de los procesos de redefinición institucional que se originaron durante los años 1980 y 1990, en donde se postulan nuevos mecanismos de intermediación del Estado con la sociedad, uno de ellos muy pregonado pero poco viabilizado fue la descentralización, que en el año de 1999 se concretó con la promulgación de la Ley de Descentralización y Participación Social, mediante la cual se produce la transferencia definitiva de competencias, funciones, equipos y recursos del gobierno central a los gobiernos locales, para el cumplimiento de una serie de actividades, entre ellas la gestión ambiental, concretándose de esta manera el establecimiento del Sistema Nacional Descentralizado de Gestión Ambiental con la vigencia de la Ley de Gestión Ambiental también en el año de 1999.

A finales de la década de los 90 del siglo pasado, la crisis política del Estado desata una gran participación de

9 Constitución de la República del Ecuador. Octubre 2008. 138 
los movimientos sociales bajo una concepción política, que genera una especie de democracia directa, en la cual los actores sociales son los que definen las decisiones del Estado, desvinculando de estos a la clase política tradicional. La participación ya no aparece solamente como instrumento de las políticas de ajuste, sino como espacio pleno bien ganado dentro de una democracia directa o participativa que busca incidir en los procesos de gestión pública.

La desintegración de los sistemas tradicionales representativos, provocan según Julio Echeverría ${ }^{10}$ tres tendencias participativas, "la una; que favorece procesos corporativos de intermediación y en muchos casos se vuelve espacio para la reproducción de intereses clientelares; la segunda, mucho más politizada, y que apunta a instaurar un modelo de democracia directa, que aparece como alternativa a la tradicional democracia representativa; y una tercera, que apunta a fortalecer procesos de empoderamiento o de autorreferencia social, de fuerte impacto en la modificación de los valores políticos".

El movimiento verde se consolida en el país a finales del siglo pasado, como consecuencia del acelerado deterioro ambiental, principalmente por el desarrollo de actividades productivas extractivas como la hidrocarburífera, minera y forestal, que han generado altos índices de contaminación y procesos de aculturación sobre todo en los pueblos de la Amazonia, estos hechos generaron y generan hasta la actualidad una alta sensibilidad social, que cuestiona el 10 Julio Echeverría, académico, de la Universidad Central del Ecuador, autor de dos libros que abordan la problemática política y constitucional en el Ecuador, La Democracia bloqueada, Quito, Letras 1997, y El Desafío Constitucional, Quito, Abya-Yala, 2006. 
manejo de los recursos naturales por parte del Estado, que favorece a intereses transnacionales en detrimento de los de la población local principalmente.

El Estado actualmente determina como una de sus políticas transversales y de cumplimiento obligatorio en todos los niveles y por todas las personas naturales y jurídicas la gestión ambiental y dentro de esta se garantiza la participación activa y permanente de las personas, comunidades, pueblos y nacionalidades en la planificación ejecución y control de toda actividad que genere impactos ambientales, lo cual ha permitido el establecimiento de comités de gestión ambiental, unidades de gestión ambiental, clubes ecológicos etc., institucionalizándose la gestión ambiental tanto en el sector público como en el privado, y esto en todas las instancias de la sociedad.

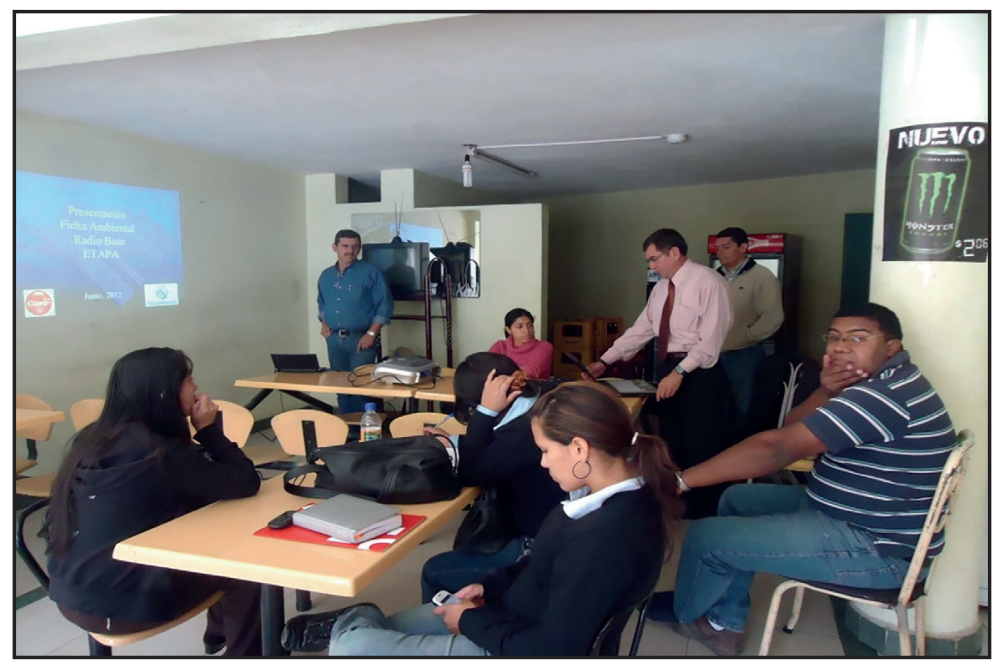




\subsection{IMPORTANCIA}

La participación social en la gestión ambiental es necesaria y muy importante, porque implica el reconocimiento del derecho colectivo de la población en general al espacio físico y político que requiere para desarrollarse, el derecho a vivir en un ambiente sano y el deber de conservarlo implica intrínsicamente el involucramiento ciudadano, porque de este depende la calidad de vida y del ambiente de la ciudad, lo que constituye en parte de la identidad de un grupo social.

El derecho a la participación es importante además porque está estrechamente relacionado con la democracia, pues la participación activa de la población determina el ejercicio pleno de sus derechos, por lo tanto los derechos humanos entre los cuales se encuentra el derecho a la vida, al ambiente, a la salud son parte de la gestión democrática de los pueblos.

La participación social se constituye como alternativa a la representación política, y es elemento principal de la democracia directa que sustituye a la democracia representativa. El empoderamiento ciudadano con capacidad de incidir políticamente y condicionar las decisiones del Estado tiende a dar funcionalidad a los mecanismos de legitimación de procesos mediante la participación social.

En definitiva, la única garantía para alcanzar el desarrollo sustentable, ambientalmente equilibrado y respetuoso de la diversidad cultural de nuestro país, que conserve la biodiversidad y la capacidad de regeneración natural de los ecosistemas y asegure la satisfacción de las necesidades 
de las presentes y futuras generaciones es, sin duda, la participación activa y permanente de las personas, pueblos, comunidades y nacionalidades en la planificación, ejecución y control de toda actividad relacionada con la gestión ambiental. Este es nuestro derecho y deber, alcanzado a través de largas y sacrificadas jornadas de lucha, que no lo podemos desaprovechar peor aún descuidar. No debemos olvidar que la situación ambiental de nuestros pueblos se debe en gran medida a la ambición desmedida y a la indiferencia humana.

\section{CAPÍTULO II}

\section{MARCO JURÍDICO E INSTITUCIONAL}

La promulgación de las políticas generales, sectoriales y locales en materia ambiental provienen de actos administrativos de las instituciones responsables de la gestión ambiental en los diferentes ámbitos según su jurisdicción (gobierno nacional, regional, provincial, municipal y parroquial), pero siempre guardando relación con las políticas nacionales, así tenemos por ejemplo que las primeras políticas básicas ambientales nacionales fueron formuladas por la CAAM (Comisión Asesora Ambiental de la Presidencia de la República, actualmente Ministerio del Ambiente) en el año de 1994 y luego regularizadas mediante Decreto Ejecutivo del Presidente de la República.

Las principales fuentes de la normativa sobre gestión ambiental expedidas por el organismo legislativo, son la Ley de Gestión Ambiental del año de 1999 codificada a septiembre de 2004, las regulaciones expedidas mediante Acuerdos Ministeriales por el organismo rector de la 
gestión ambiental del país, el Ministerio de Ambiente, como es el caso del Texto Unificado de Legislación Ambiental Secundaria que regula el Sistema Único de Manejo Ambiental 2003, que contiene normas secundarias para la gestión ambiental, docuento reformado a mayo de 2015 .

Lo mismo ha sucedido con las políticas ambientales sectoriales cuyas fuentes provienen de las agencias públicas responsables de los llamados sectores estratégicos, ejemplo: agua, biodiversidad, forestal, energía que promulgan sus políticas ambientales a través de los organismos responsables de la gestión de estos recursos, en concordancia con las políticas nacionales y las expide mediante decreto la máxima autoridad del Estado.

Enel caso de los gobiernos autónomos descentralizados, estos mediante actos legislativos de sus organismos colegiados, dictan sus propias políticas ambientales y sus normas para la gestión ambiental a través de las ordenanzas, siempre en concordancia con las políticas y normas nacionales, más aún cuando los GAD han sido acreditados por la autoridad ambiental nacional.

Las principales fuentes normativas nacionales de políticas y gestión ambiental, con las que actualmente cuenta el país son las siguientes: la Constitución de la República 2008, Código Orgánico de Organización Territorial, Autonomía y Descentralización COOTAD 2010, Ley de Gestión Ambiental 1999, Ley Forestal y de Conservación de Áreas Naturales y Vida Silvestre 1981, Ley de Biodiversidad 1996, Ley de Minería 2010, Texto Unificado de Legislación Ambiental Secundaria del Ministerio del Ambiente 2003, ordenanzas provinciales y municipales principalmente expedidas luego de la vigencia 
de la Constitución. A esto debemos sumar los convenios y tratados internacionales ratificados por el Ecuador, que son jurídicamente vinculantes, constituyéndose en la base de la política y gestión ambiental como el de Río, el más relacionado con el tema de investigación que nos ocupa.

\subsection{LEYES}

Las leyes son cuerpos normativos que regulan aspectos generales en unos casos y en otros específicos del convivir social sobre ciertas materias o actividades, en el caso de la participación ciudadana en gestión ambiental tenemos relación con las leyes descritas a continuación:

\begin{tabular}{|l|l|}
\hline \multicolumn{2}{|c|}{ CUERPO NORMATIVO: Ley de Gestión Ambiental 1999. } \\
\hline \multicolumn{1}{|c|}{ CONTENIDO } & \multicolumn{1}{c|}{ APLICACIÓN } \\
\hline $\begin{array}{l}\text { Art. 12. literal } \\
\text { g) Garantía al } \\
\text { acceso de la } \\
\text { información } \\
\text { pública } \\
\text { ambiental. }\end{array}$ & $\begin{array}{l}\text { Es obligación de las instituciones del Estado del Sistema } \\
\text { a toda persona el acceso a la información previa a la toma } \\
\text { de decisiones de la administración pública relacionada con } \\
\text { la protección del ambiente. }\end{array}$ \\
\hline $\begin{array}{l}\text { Art. 28. } \\
\text { Derecho de } \\
\text { participar en } \\
\text { la gestión } \\
\text { ambiental. }\end{array}$ & $\begin{array}{l}\text { Toda persona tiene el derecho a participar en la gestión } \\
\text { ambiental a través de los diversos mecanismos, regulados } \\
\text { en la Ley de Participación Social. }\end{array}$ \\
\hline $\begin{array}{l}\text { Art. 39. } \\
\text { Programas de } \\
\text { Monitoreo. }\end{array}$ & $\begin{array}{l}\text { Las instituciones encargadas de la administración de los } \\
\text { recursos naturales, control de la contaminación ambiental, } \\
\text { establecerán con participación social programas de } \\
\text { monitoreo de dichos recursos. }\end{array}$ \\
\hline $\begin{array}{l}\text { Art. 41. } \\
\text { Acción } \\
\text { pública. }\end{array}$ & $\begin{array}{l}\text { Con el fin de proteger los derechos ambientales individuales } \\
\text { o colectivos, se concede acción pública para que cualquier } \\
\text { persona denuncie la violación de las normas de medio } \\
\text { ambiente. }\end{array}$ \\
\hline
\end{tabular}




\subsection{REGLAMENTOS}

Comprenden el conjunto de normas de procedimiento necesarias para la aplicación de las disposiciones contenidas en las leyes, entre los más importantes contamos con los siguientes:

\begin{tabular}{|c|c|}
\hline \multicolumn{2}{|c|}{$\begin{array}{c}\text { CUERPO NORMATIVO: Texto Unificado de Legislación } \\
\text { Ambiental Secundaria del Ministerio del Ambiente Libro VI de } \\
\text { Calidad Ambiental } 2003 .\end{array}$} \\
\hline CONTENIDO & APLICACIÓN \\
\hline $\begin{array}{l}\text { Art. } 20 . \\
\text { Participación } \\
\text { ciudadana. }\end{array}$ & $\begin{array}{l}\text { La finalidad de la participación ciudadana en la gestión } \\
\text { ambiental, es considerar e incorporar los criterios y } \\
\text { observaciones de la ciudadanía, especialmente la } \\
\text { población directamente afectada de una obra o proyecto. }\end{array}$ \\
\hline \multicolumn{2}{|c|}{$\begin{array}{c}\text { CUERPO NORMATIVO: Decreto Ejecutivo No. } 1040 \text { de } \\
\text { mayo } 2008 \text { que contiene el Reglamento de aplicación de los } \\
\text { mecanismos de participación social establecidos en la Ley de } \\
\text { Gestión Ambiental. }\end{array}$} \\
\hline Art. 3. Objeto. & $\begin{array}{l}\text { El objeto principal de este Reglamento es contribuir } \\
\text { a garantizar el respeto al derecho colectivo de todo } \\
\text { habitante a vivir en un ambiente sano, ecológicamente } \\
\text { equilibrado y libre de contaminación. }\end{array}$ \\
\hline Art. 4. Fines. & $\begin{array}{l}\text { El reglamento tiene como fines: Precisar los mecanismos } \\
\text { determinados en la Ley de Gestión Ambiental a ser } \\
\text { utilizados en los procedimientos de participación social; } \\
\text { Permitir a la autoridad pública conocer los criterios de la } \\
\text { comunidad en relación a una actividad o proyecto que } \\
\text { genere impacto ambiental; Contar con los criterios de la } \\
\text { comunidad, como base de la gobernabilidad y desarrollo } \\
\text { de la gestión ambiental; y, Transparentar las actuaciones y } \\
\text { actividades que puedan afectar al ambiente, asegurando } \\
\text { a la comunidad el acceso a la información disponible. }\end{array}$ \\
\hline
\end{tabular}




\begin{tabular}{|c|c|}
\hline $\begin{array}{l}\text { Art. 5. Sistema } \\
\text { Nacional } \\
\text { Descentralizado } \\
\text { de Gestión } \\
\text { Ambiental. }\end{array}$ & $\begin{array}{l}\text { El Sistema Nacional Descentralizado de Gestión } \\
\text { Ambiental es un mecanismo de coordinación transectorial, } \\
\text { interacción y cooperación entre los distintos ámbitos, } \\
\text { sistemas y subsistemas de manejo ambiental y de } \\
\text { gestión de recursos naturales. En el sistema participará } \\
\text { la sociedad civil. }\end{array}$ \\
\hline $\begin{array}{l}\text { Art. } 8 . \\
\text { Mecanismos. }\end{array}$ & $\begin{array}{l}\text { Audiencias, presentaciones públicas, reuniones } \\
\text { informativas, asambleas, mesas ampliadas y foros } \\
\text { públicos de diálogo; } \\
\text { Talleres de información, capacitación y socialización } \\
\text { ambiental. }\end{array}$ \\
\hline $\begin{array}{l}\text { Art. } 9 . \\
\text { Alcance de la } \\
\text { participación } \\
\text { social. }\end{array}$ & $\begin{array}{l}\text { La participación social es un elemento transversal y } \\
\text { trascendental de la gestión ambiental. En consecuencia, } \\
\text { se integrará principalmente durante las fases de toda } \\
\text { actividad o proyecto propuesto, especialmente las } \\
\text { relacionadas con la revisión y evaluación de impacto } \\
\text { ambiental. }\end{array}$ \\
\hline $\begin{array}{l}\text { Art. } 12 . \\
\text { Autoridad } \\
\text { Competente. }\end{array}$ & $\begin{array}{l}\text { Las instituciones y empresas del Estado, en el área } \\
\text { de sus respectivas competencias, son las autoridades } \\
\text { competentes para la organización, desarrollo y aplicación } \\
\text { de los mecanismos de participación social, a través de la } \\
\text { dependencia técnica correspondiente. }\end{array}$ \\
\hline $\begin{array}{l}\text { Art. 13. Del } \\
\text { Financiamiento. }\end{array}$ & $\begin{array}{l}\text { El costo del desarrollo de los mecanismos de participación } \\
\text { social será cubierto por la autoridad ambiental de } \\
\text { aplicación responsable que deba aprobar el Estudio de } \\
\text { Impacto Ambiental, dichos costos serán retribuidos por el } \\
\text { promotor del proyecto o actividad a la autoridad ambiental } \\
\text { de aplicación }\end{array}$ \\
\hline $\begin{array}{l}\text { Art. } 17 . \\
\text { Información } \\
\text { necesaria y } \\
\text { procedencia de } \\
\text { la participación } \\
\text { social. }\end{array}$ & $\begin{array}{l}\text { Para iniciar el proceso de participación social, la autoridad } \\
\text { competente debe contar con la información necesaria } \\
\text { para ponerla a disposición de la comunidad y permitir que } \\
\text { esta emita sus criterios. }\end{array}$ \\
\hline $\begin{array}{l}\text { Art. 23.- Espacios } \\
\text { de veedurías } \\
\text { ciudadanas. }\end{array}$ & $\begin{array}{l}\text { Para monitorear y exigir la rendición de cuentas a la } \\
\text { gestión ambiental, los sujetos de participación social } \\
\text { podrán conformar veedurías ciudadanas. }\end{array}$ \\
\hline $\begin{array}{l}\text { Art. 24.- } \\
\text { Inejecutabilidad } \\
\text { de actos y } \\
\text { contratos. }\end{array}$ & $\begin{array}{l}\text { La actividad o proyecto que genere impacto ambiental, así } \\
\text { como los actos y contratos que se deriven de la misma, } \\
\text { serán inejecutables si no cumplen con uno o más de los } \\
\text { requisitos del procedimiento de participación social. }\end{array}$ \\
\hline
\end{tabular}




\subsection{ORDENANZAS}

Son normas de carácter especial dictadas por los gobiernos seccionales, relativas a la organización y desarrollo de su jurisdicción, en este caso, el Gobierno Autónomo Descentralizado Municipal del cantón Cuenca, a través del Concejo Cantonal. es uno de los Municipios del Ecuador, que cuenta con una amplia noma sobre gestión ambienal, lo que le ha puesto a la vanguardia dentro de esta rama en el país. así tenemos que contó con la primera Unidad de Gestión Ambiental. administra la única área natural protegida descentralizada del Sistema Nacional y cuenta con procesos de descentralización y desconcentración sobre el manejo y administración de recursos como agua, aire, biodiversidad, que le han permitido generar una serie de normas mediante ordenanzas que se consideran como referente para el Estado.

\begin{tabular}{|l|l|}
\hline \multicolumn{2}{|c|}{$\begin{array}{l}\text { CUERPO NORMATIVO: Ordenanza de Creación de la Comisión de } \\
\text { Gestión Ambiental (CGA). 22-05-1997 }\end{array}$} \\
\hline \multicolumn{1}{|c|}{ CONTENIDO } & \multicolumn{1}{c|}{ APLICACIÓN } \\
\hline $\begin{array}{l}\text { Art. 1. } \\
\text { Establecimiento } \\
\text { de la Comisión de } \\
\text { Gestión Ambiental. }\end{array}$ & $\begin{array}{l}\text { La CGA es un organismo autónomo descentralizado } \\
\text { dotado de autoridad administrativa, ejerce la autoridad } \\
\text { ambiental de aplicación responsable en el cantón } \\
\text { Cuenca. }\end{array}$ \\
\hline Art. 2. Objetivos. & $\begin{array}{l}\text { Fortalecer el liderazgo y autonomía municipal en lo } \\
\text { relativo a la gestión ambiental; } \\
\text { Integrar a las instituciones vinculadas con la protección } \\
\text { del ambiente; } \\
\text { Mejorar las condiciones ambientales del cantón; } \\
\text { Promover la implementación del Sistema de Gestión } \\
\text { Ambiental. }\end{array}$ \\
\hline
\end{tabular}




\begin{tabular}{|l|l|}
\hline Art. 3. Funciones. & $\begin{array}{l}\text { Acatar y velar por el cumplimiento de las políticas, } \\
\text { estrategias y disposiciones legales ambientales locales; } \\
\text { Coordinar acciones entre los organismos públicos y } \\
\text { privados para lograr la sustentabiliad; } \\
\text { Promover la actualización y generación de normas } \\
\text { ambientales; } \\
\text { Promover la investigación, desarrollo y aplicación de } \\
\text { herramientas de gestión ambiental; } \\
\text { Vigilar y disponer que todo proyecto que requiere de } \\
\text { EslA y de planes de manejo ambiental se ejecuten } \\
\text { oportuna y adecuadamente; } \\
\text { Otorgar licencias ambientales; } \\
\text { Ejercer acciones de procuraduría ambiental; } \\
\text { Ejercer las competencias transferidas por el Minisiterio } \\
\text { del Ambiente. }\end{array}$ \\
\hline Art. 5. Estructura. & $\begin{array}{l}\text { Nivel directivo o Directorio; } \\
\text { Nivel ejecutivo constituido por el Director Ejecutivo; y, } \\
\text { Nivel operativo integrado por las Unidades Técnica y } \\
\text { Administrativa-Financiera. }\end{array}$ \\
\hline Art. 8. & Son aprobados por el Directorio. \\
resoluciones. & \\
\hline Recop y & \\
\hline
\end{tabular}

Recopilación y sistematización: Franklin Bucheli García 2014.

\subsection{INSTITUCIONALIDAD}

El marco institucional para el desarrollo de la gestión ambiental se encuentra establecido en el Sistema Nacional Descentralizado de Gestión Ambiental, regulado en la Ley de Gestión Ambiental y reconocido por la Constitución de la República, en la cual se determinan las competencias ambientales desconcentradas y descentralizadas de los gobiernos nacional, regional, provincial, municipal y parroquial.

El ejercicio de la competencia ambiental dentro del Sistema Nacional Descentralizado se lo ejerce a través del Sistema Único de Manejo Ambiental, en el que se 
determinan las instituciones nacionales, sectoriales y seccionales que según la ley tienen facultad para la realización de actividades relacionadas con la prevención y control de la contaminación ambiental, y administración de los recursos naturales. Así tenemos que la autoridad ambiental nacional es el Ministerio del Ambiente; la autoridad ambiental de aplicación son los Ministerios u organismos de la función ejecutiva, a los que por ley o acto normativo se les ha transferido o delegado una competencia ambiental; la autoridad ambiental de aplicación responsable es la institución que ha acreditado ante el Sistema Único de Manejo Ambiental un sistema de evaluación de impactos ambientales; y la autoridad ambiental de aplicación cooperante que son las instituciones no acreditadas ante el Sistema Único de Manejo Ambiental, pero que participan en el proceso de evaluación de impactos ambientales emitiendo a las autoridades ambientales de aplicación responsable su informe en función de sus competencias.

El Gobierno Autónomo Descentralizado Municipal del cantón Cuenca, cuenta desde el año de 1997 con la Comisión de Gestión Ambiental, órgano municipal descentralizado, integrador, de coordinación transectorial, de integración y cooperación de la participación pública y privada, que lidera la gestión ambiental, entidad que desde diciembre de 2005 es reconocida por el Ministerio del Ambiente como Autoridad Ambiental de Aplicación Responsable que la mantiene hasta la actualidad. En el año 2006 se fortalece la institucionalidad ambiental local con la suscripción del convenio de transferencia definitiva de competencias ambientales del Gobierno Nacional al Gobierno Autónomo Descentralizado Municipal del cantón Cuenca. 
Cuenca es un cantón reconocido nacional e internacionalmente por conservar y aprovechar sustentablemente sus recursos naturales, por lo mismo las administraciones municipales se han preocupado por contar con una institución técnica, solvente, que responda eficientemente ante el nuevo reto de la gestión ambiental fundamentada en la participación y veeduría social, por ello la CGA cuenta con una Unidad Administrativa de Participación Social con personal especializado para garantizar la participación ciudadana en la información, educación, y decisión de los procesos ambientales del cantón.

Lo manifestado demuestra los resultados generados por la Comisión de Gestión Ambiental de Cuenca, desde que se incorpora la participación y veeduría social como parte de los procesos de gestión ambiental. Así tenemos que en el año 2009 se tramitaron 64 fichas ambientales; 24 estudios de impacto ambiental; 57 estudios de impacto ambiental expost; y 16 licencias ambientales. En el año 2010, se despachan 1350 fichas ambientales; 25 estudios de impacto ambiental; 43 estudios de impacto ambiental expost; y 31 licencias ambientales. En el año 2011 se atienden 2160 fichas ambientales; 28 estudios de impacto ambiental; 84 estudios de impacto ambiental expost; y 84 licencias ambientales. Hasta septiembre de 2012 se sustancian 1640 entre fichas ambientales, estudios de impacto ambiental y licencias ambientales, dando un total de 5.606 instrumentos de evaluación ambiental.

De todos los instrumentos de evaluación ambiental gestionados, el $78 \%$ se han sometido al proceso de participación y veeduría social por así determinarlo la 
reglamentación correspondiente, que establece para el caso de fichas ambientales solamente las relacionadas con la implementación de radio bases de telefonía celular, tienen que hacer. En lo que respecta a estudios de impacto ambiental y estudios de impacto ambiental expost, se cumple con este proceso los que están dentro de la categoría III; y, en lo que respecta a las licencias ambientales en todos los casos.

\subsection{MECANISMOS}

La participación social es un elemento transversal y trascendental de la gestión ambiental, en consecuencia, debe estar integrada durante las fases de toda actividad o proyecto propuesto, especialmente las relacionadas con la revisión y evaluación de impacto ambiental. En este sentido los mecanismos de participación ciudadana que se vienen desarrollando en la gestión ambiental en Cuenca y se encuentran debidamente regulados son los siguientes:

* Audiencias o presentaciones públicas, reuniones informativas, asambleas, mesas ampliadas y foros públicos de diálogo. Mediante los cuales se presentan el contenido de los estudios de impacto y el plan de manejo ambiental a fin de receptar observaciones de la colectividad.

- Talleres de información, capacitación y socialización ambiental. Son dispuestos por la autoridad ambiental, cuyo objeto, a más de la información del proyecto, permite al promotor identificar e insertar medidas mitigadoras y compensatorias.

* Encuestas de percepción y satisfactoriedad a los moradores sobre el desarrollo de proyectos, obras, 
actividades o servicios. Se las realiza principalmente en la zona de influencia directa del proyecto para establecer el criterio de la ciudadanía sobre el mismo.

* Campañas de difusión y sensibilización ambiental a través de los medios de comunicación, para motivar el involucramiento y la participación social en la gestión ambiental.

* Mecanismos de información pública. Los instrumentos de evaluación de impacto ambiental deben ser visualizados y puestos a disposición de la ciudadanía; deben ser de fácil acceso, y se debe contar con personal técnico para la explicación de su contenido.

* Reparto de documentación informativa sobre el proyecto. Se lo hace generalmente con la convocatoria del taller de información y difusión técnica del proyecto por parte del promotor.

* Página web de la CGA. El estudio de impacto y plan de manejo ambiental tiene que ser publicado en la página web de la entidad ambiental.

* Los demás medios que permitan el acceso de la comunidad a la información disponible sobre actividades, obras, proyectos que puedan afectar al ambiente.

La información que se proporcione a la comunidad del área de influencia en función de las características socio-culturales deberá responder a criterios tales como: lenguaje sencillo y didáctico, información completa y veraz, en lengua nativa, de ser el caso; y procurará un alto nivel de participación.

De acuerdo con los criterios señalados puede ser necesario, en ciertas ocasiones, aplicar varios mecanismos de participación en función de las características socio- 
culturales de la población, debiendo fundamentarse la selección de estos mecanismos por parte de la autoridad ambiental competente.

La aplicación de estos mecanismos de participación ciudadana para la aprobación de instrumentos de evaluación ambiental desde su vigencia en el cantón ha tenido el siguiente desarrollo:

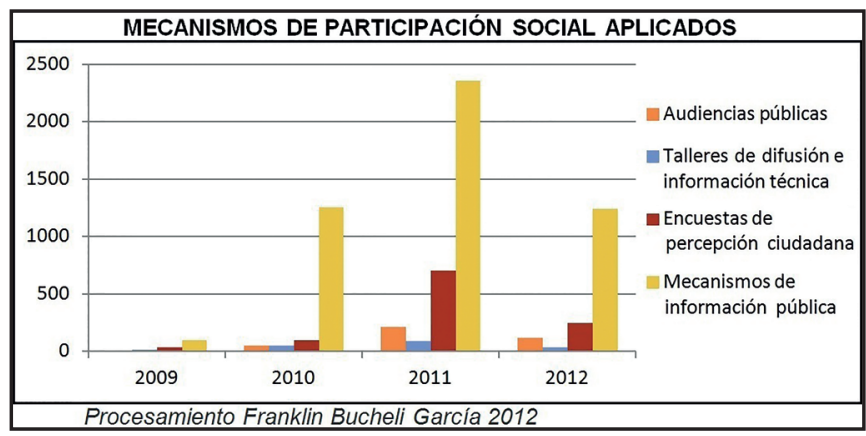

\section{CAPÍTULO III}

\section{PARTICIPACIÓN Y VEEDURÍA SOCIAL}

Es menester indicar que en estos procesos de participación social, la autoridad ambiental considera las observaciones de la ciudadanía que tengan fundamento técnico y sean económicamente viables, para que las actividades, obras, proyectos o servicios que puedan generar impactos ambientales significativos se cumplan bajo condiciones ambientales que garanticen minimizar los impactos con inversiones económicas que no pongan en riesgo la ejecución de la actividad, y de esta manera 
viabilizar técnica y económicamente los proyectos sin afectar las características ambientales, las condiciones sociales y el desarrollo económico del cantón.

Para ello la entidad ambiental de aplicación responsable debe poner a disposición de la ciudadanía los informes de auditorías, estudios y otros documentos ambientales, estos documentos deben estar archivados en las oficinas de la entidad ambiental de manera permanente y ser difundidos en el portal de internet mientras dure el proceso de revisión y aprobación de los instrumentos de evaluación ambiental, toda esta información es de carácter público.

\section{1 ÁMBITO}

El ámbito de aplicación de la participación y veeduría social en los procesos de aprobación de instrumentos de evaluación de impacto ambiental en Cuenca, tiene relación con la categorización de actividades productivas que pueden ser desarrolladas tanto en la zona urbana como rural del cantón, de conformidad con la Ordenanza del Uso y ocupación del Suelo. En este sentido el Directorio de la Comisión de Gestión Ambiental del Gobierno Autónomo Descentralizado Municipal del cantón en el mes de marzo de 2012 actualiza esta lista taxativa, determinando la categorización de actividades productivas del cantón y el instrumento de evaluación de impacto ambiental que requieren para su desarrollo.

Por lo expuesto los procesos de participación y veeduría social que deben llevarse a cabo a través de los diferentes mecanismos establecidos en la normativa local, son todos los estudios de impacto ambiental contemplados en la 
lista taxativa de actividades productivas que requieran de licencia ambiental, es decir los que constan en las categorías II y III y adicionalmente las fichas ambientales que deben presentarse para el emplazamiento de las estaciones de las radio bases para telefonía celular por parte de los operadores de telecomunicaciones móviles.

Así tenemos que desde el 2009 a septiembre del 2012, se han tramitado bajo procesos de participación y veeduría social un total de 5014 fichas ambientales; 127 estudios de impacto ambiental; 284 estudios de impacto ambiental expost; y, 181 licencias ambientales en el cantón Cuenca.

\subsection{PRINCIPIOS}

La legitimidad está dada por el ejercicio de la autoridad ambiental, la misma que se genera en la Constitución de la República y la Ley de Gestión Ambiental que regula el Sistema Nacional Descentralizado de Gestión Ambiental, en el cual se reconoce a la autoridad ambiental de aplicación responsable, que en este caso es el Gobierno Autónomo Descentralizado Municipal del cantón Cuenca, que lo ejerce a través de la Comisión de Gestión Ambiental y que forma parte del Sistema Único de Manejo Ambiental del país, conforme la acreditación realizada por la autoridad ambiental nacional, es decir el Ministerio del Ambiente.

La representatividad se relaciona con la participación directa de la ciudadanía en la toma de decisiones, planificación y gestión de los asuntos públicos. Uno de ellos sin duda es la gestión ambiental, esta participación se fundamentada en la igualdad, autonomía, deliberación, respeto, solidaridad e interculturalidad, siendo por lo tanto 
un derecho que se lo ejerce a través de los mecanismos de la democracia representativa, directa y comunitaria. Para ello se reconocen todas las formas de organización de la sociedad, como expresión de la soberanía popular.

En los procesos de evaluación de impactos ambientales, la participación ciudadana se la puede ejercer en forma individual o en representación de la colectividad, generalmente está llamada a intervenir y pronunciarse sobre estos procesos la población establecida en el área de influencia de la obra, proyecto o actividad; asimismo deben participar los representantes legítimamente electos de los gobierno seccionales, por ser quienes representan a la población del área de influencia del proyecto; también esta representatividad la ejercen las organizaciones de diferente índole que representan a la población del área de influencia del proyecto.

Sin embargo de lo anotado los procesos de participación y veeduría social en materia ambiental, bajo ninguna circunstancia pueden excluir a cualquier grupo y organización social de intervenir en los mismos, porque estos son totalmente abiertos y públicos.

\subsection{MOMENTOS}

Estos momentos de participación social se encuentran establecidos en la regulación determinada por la autoridad ambiental de aplicación responsable, considerándose como obligatorios y mínimos dos:

a. Durante la elaboración de los términos de referencia, previo a la aprobación de la autoridad ambiental. 
b. Durante el informe preliminar del estudio de impacto ambiental, previo a la presentación a la autoridad ambiental para su aprobación.

Como resultado del monitoreo realizado la intervención de los actores sociales en los procesos de participación y veeduría social ha sido sometida a consideración de la autoridad cantonal.

\subsection{SUJETOS}

Como se ha manifestado anteriormente estos procesos de participación y veeduría social son abiertos y públicos, en tal virtud nadie que quiera ser parte de los mismos puede ser excluido.

Bajo esta premisa la participación y veeduría social dentro de los procesos de evaluación de estudios de impacto ambiental, está dirigida de forma general a toda la población y en particular de forma prioritaria a la comunidad establecida dentro del área de influencia directa del lugar donde se realizará la actividad, proyecto o servicio que pueda generar impactos ambientales. Esta área es determinada por la autoridad ambiental de aplicación responsable, en el momento que apruebe la metodología para el desarrollo de la participación social.

Delimitada el área de influencia directa del proyecto, es procedente, bajo los principios de legitimidad y representatividad, contar con la participación de los siguientes actores sociales e institucionales, que de acuerdo al monitoreo realizado son los que con frecuencia participan: 
- Autoridades de los gobiernos seccionales. (Alcaldes, prefectos, juntas parroquiales).

- Representantes de entidades de control local. (Dirección de Control Municipal, Unidad de Gestión Ambiental, Empresa Municipal de Aseo, Empresa Municipal de Agua Potable, entre otras).

- Autoridades locales representantes de entidades nacionales, relacionados con el proyecto. (Superintendencias, direcciones regionales, directores provinciales).

* Organizaciones comunitarias legalmente establecidas y representadas. (Asociación de barrios, gremios, comités).

* Personas que habitan en el área de influencia directa del proyecto.

\subsection{CONVOCATORIAS}

En la gestión ambiental cantonal las convocatorias a los mecanismos de participación y veeduría social se deben realizar utilizando medios de amplia difusión pública, que garanticen a la población el acceso a la información, debiéndose incluir direcciones donde pueda consultarse el documento, entre estas la página web donde se encuentra disponible la versión digital del estudio de impacto ambiental; la metodología a cumplirse para el proceso de participación social y la fecha hasta cuándo se pueden hacer y presentar las observaciones para la recepción de criterios.

Las convocatorias para estos procesos en el cantón Cuenca se realizan simultáneamente mediante una 
publicación, por dos días consecutivos en uno de los diarios de mayor circulación del cantón; y, mediante el envío de comunicaciones escritas a los sujetos de la participación y veeduría social.

Para constancia de lo indicado la autoridad ambiental exige al facilitador ambiental, que en la presentación del informe final del proceso de participación y veeduría social, presente los ejemplares de las páginas del periódico en el cual se publicaron las convocatorias.

La autoridad ambiental es la encargada de verificar que el promotor utilice los medios de convocatoria indicados, para lograr una adecuada difusión de la convocatoria al proceso de participación y veeduría social.

Las convocatorias que deban realizarse, según las exigencias de la autoridad ambiental, son a costo del promotor.

De la revisión de los procesos efectuados durante esta investigación se evidencia el cumplimiento de la norma, en caso contrario el proceso mismo no podía haberse desarrollado, dado que estos son procedimientos de cumplimiento obligatorio para la validez de los mismos.

\subsection{RECEPCIÓN DE CRITERIOS Y SISTEMATIZACIÓN}

Cumplidas las publicaciones dispuestas por la autoridad ambiental local, se debe llevar a cabo en el término de ocho días el taller de información técnica, difusión y socialización ambiental, efectuado este taller la comunidad cuenta con el término de siete días para presentar 
criterios y observaciones al estudio de impacto ambiental socializado, en caso de que estas observaciones no hayan sido presentadas en el taller de difusión y socialización.

Las observaciones y criterios que formule la comunidad deben ser documentados y sistematizados, con el propósito de establecer los tipos de comentarios en función de su origen, tratamiento, y forma de incorporación al estudio de impacto ambiental para su aplicación.

Para la recepción y posterior sistematización de los criterios de la comunidad, la autoridad ambiental de Cuenca, tiene establecidos los siguientes mecanismos:

$>$ Actas de los talleres de información técnica, difusión y socialización ambiental.

> Presentación por escrito de observaciones a la autoridad ambiental.

El facilitador ambiental designado por la autoridad ambiental es el responsable de elaborar y presentar el informe de sistematización, el mismo que entre otros aspectos debe contener:

> Las actividades más relevantes del proceso de difusión y socialización.

$>\mathrm{El}$ análisis de los posibles conflictos socioambientales.

> Fundamentación técnica, económica y jurídica de los conflictos socio-ambientales.

$>$ Propuesta de soluciones a los conflictos socioambientales.

El informe de sistematización del proceso de participación social debe ser presentado a la autoridad ambiental para su revisión y una vez aprobado se tiene 
que incluir en el estudio de impacto ambiental como documento habilitante.

En el caso de que no exista intervención por parte de los sujetos de participación y veeduría social dentro de estos procesos de gestión ambiental, a pesar de haber sido convocados, o en el caso de que se opongan a su realización, estas circunstancias no constituyen de ninguna manera causas de nulidad del proceso de participación social, ni tampoco lo suspende. El facilitador debe poner en conocimiento de la autoridad ambiental para que continúe el trámite de aprobación del instrumento de evaluación de impacto ambiental.

\subsection{SANCIONES}

Los gobiernos autónomos descentralizados, a través de los funcionarios competentes, son los encargados de juzgar las infracciones a la norma ambiental, por lo mismo ejercen la potestad sancionadora en el ámbito administrativo.

Los municipios, que es el motivo de este estudio, tienen competencia para establecer sanciones administrativas mediante actos legislativos a través del Concejo Cantonal, para su juzgamiento y hacer cumplir la resolución en ejercicio de la potestad sancionadora.

La potestad sancionadora se rige por principios de legalidad, proporcionalidad, tipicidad, responsabilidad, irretroactividad e imprescriptibilidad.

Cuando se tratan de infracciones flagrantes, se podrán emplear medidas provisionales y cautelares de naturaleza 
real para asegurar la inmediación del presunto infractor, la aplicación de la sanción y precautelar a las personas, los bienes y el ambiente.

Los procedimientos establecidos para el desarrollo del proceso de participación y veeduría social se encuentran sujetos al control de la autoridad ambiental, por lo mismo la competencia para conocer, sustanciar y sancionar las infracciones relativas a las contravenciones por el incumplimiento de la ordenanza que regula este proceso es la Comisaría Ambiental del cantón Cuenca, autoridad que por denuncia, informe técnico o de oficio, procederá con el inicio del trámite de juzgamiento administrativo correspondiente.

El procedimiento de juzgamiento se encuentra fundamentado en las disposiciones de la Constitución de la República, el Código Orgánico de Organización Territorial, Autonomía y Descentralización y la Ordenanza para la Aplicación del Subsistema de Evaluación de Impacto Ambiental del cantón Cuenca, bajo los principios del debido proceso, las reglas de la sana crítica y el principio jurídico ambiental precautelatorio.

Este proceso administrativo sancionador, inicia mediante auto motivado que determina con precisión el hecho acusado, la persona presuntamente responsable del hecho, la norma que tipifica la infracción y la sanción a imponerse en caso de demostrarse la responsabilidad. En el mismo auto se deben solicitar los informes y documentos que sean necesarios para el esclarecimiento del hecho.

El auto de inicio del proceso es notificado al presunto infractor, concediéndole el término de cinco días para que lo conteste, con la contestación o en rebeldía, se debe 162 
abrir la causa a prueba por un plazo de diez días, cumplido el mismo se debe dictar la resolución correspondiente.

Independientemente cuando la Comisaría Ambiental, presuma que la infracción cometida puede ser delito ambiental, remitirá el expediente a la Fiscalía pertinente para su investigación.

\section{Tipificación de infracciones:}

a. El incumplimiento del desarrollo del proceso de participación y veeduría social, para la aprobación de las fichas ambientales y estudios de impacto ambiental que requieran licencia ambiental como es el caso de actividades categorizadas como II será sancionado con 20 salarios básicos unificados; y para las actividades categorizadas como III con 30 salarios básicos unificados.

b. El incumplimiento del plazo ( 8 días desde la última publicación) establecido para la realización de taller de información técnica, difusión y socialización ambiental, será sancionado con una multa de 20 salarios básicos unificados para las actividades categorizadas como Il; y, 30 salarios básicos unificados para las actividades categorizadas como III, en la lista taxativa de actividades productivas.

El cumplimiento de la norma dentro de los procesos de participación y veeduría social, es bastante alta si se considera el número de procesos desarrollados, por lo mismo se puede manifestar que el incumplimiento de la norma y las sanciones establecidas constituyen una excepción a la regla, pues en el año que más infracciones 
se sustancian y sancionan son 16 trámites administrativos por incumplimiento de los plazos establecidos para el desarrollo de la participación y veeduría social.

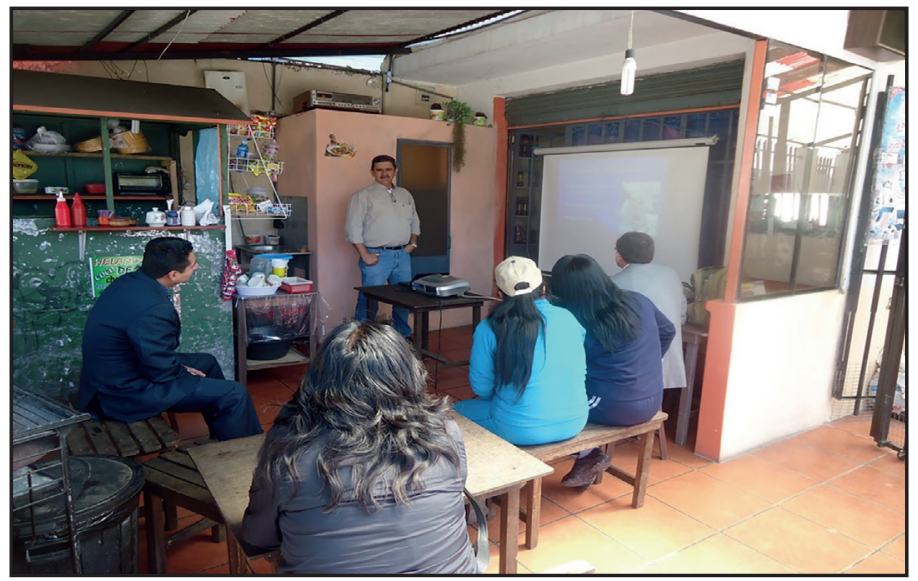

\section{CONCLUSIONES}

Luego de haber realizado la revisión bibliográfica y la investigación de campo sobre la participación y veeduría ciudadana en la aprobación de instrumentos de evaluación ambiental por parte de la autoridad ambiental del cantón Cuenca, se ha llegado a las siguientes conclusiones:

- A pesar de que la reglamentación para la participación y veeduría social para la aprobación de instrumentos de evaluación ambiental rige a partir de mayo del año 2008, en el cantón Cuenca se inicia con estos procesos a partir de enero del 2009 dado que se hizo necesario adecuar la Ordenanza para la aplicación del Subsistema de Evaluación ambiental. 
- Desde el año 2009 hasta septiembre de 2012, la Comisión de Gestión Ambiental de Cuenca, desarrolla 5.606 trámites relacionados con la aprobación de fichas ambientales, estudios de impacto ambiental y concesión de licencias ambientales; 4.732 se sometieron a los procesos de participación y veeduría social mediante los mecanismos establecidos en la Ordenanza del Subsistema de Evaluación de Impacto Ambiental, por así disponerlo la lista taxativa para el desarrollo de actividades productivas. Esto representa el $78 \%$ de los instrumentos de evaluación ambiental aprobados.

- El mecanismo de participación social más utilizado para la socialización de los instrumentos de evaluación ambiental es el de información pública, utilizando para el efecto el sitio web de la Comisión de Gestión Ambiental, seguido por encuestas de percepción ciudadana realizadas por los consultores o facilitadores, luego vienen las audiencias y públicas y por último los talleres de difusión en información técnica.

- Los actores sociales e institucionales con mayor incidencia en los procesos de participación y veeduría social son la ciudadanía y la autoridad ambiental local; y los de menor intervención son los representantes de otras institucionales locales y nacionales que tienen relación con la obra, servicio o actividad sometida a estos procesos.

- Las observaciones que se desarrollan por parte de la ciudadanía y otros actores, tienen que ver con aspectos técnicos, ambientales, económicos y legales principalmente. Se destacan entre los técnicos, características productivas; en los 
ambientales, medidas de mitigación de impactos; en los económicos, presupuesto para aplicación del plan de manejo ambiental; $y$ en el legal, situaciones relacionadas con el uso del suelo y la compatibilidad de la actividad o proyecto a emplazarse en el lugar.

- Por todo lo expuesto, el procedimiento para llevar a cabo los procesos de participación y veeduría social han sido cumplidos tanto por la autoridad ambiental local, los consultores y facilitadores ambientales, lo que constituye una oportunidad muy bien aprovechada por la ciudadanía para involucrarse en estos procesos y sobre todo dar a conocer sus inquietudes y sugerencias a fin de que los mismos se los lleve en función de los intereses colectivos, situación que anteriormente a la vigencia de esta norma no era posible.

\section{RECOMENDACIONES}

1. La información y difusión del contenido de los instrumentos de evaluación ambiental deben mejorar y ampliarse, mediante mecanismos que alienten a una mayor participación social, sobre todo en la población de áreas rurales, para lo cual se sugiere utilizar carteles que pueden exhibirse en lugares de bastante concurrencia, como por ejemplo plazas públicas, iglesias, despachos de autoridades como Tenencia Política etc.

2. Es necesario desarrollar un amplio programa de capacitación para alcanzar una cultura ambiental ciudadana que permita recoger observaciones que aporten y viabilicen la ejecución de los proyectos 
y no únicamente que se presenten muchas veces oposición a los mismos sin ninguna fundamentación, afectando incluso por esta circunstancia a posibilidades de mejoramiento socio-económico y ambiental de la gente y el territorio.

3. Para que los procesos de participación y veeduría social se constituyan en una verdadera herramienta técnica, legal y social que realmente contribuya a mejorar los procesos productivos, de infraestructura, y servicios, es necesario contar con una sola propuesta metodológica para la ejecución de la participación social, y de esta manera desarrollar una sistematización de la misma, para evidenciar el grado de cumplimiento de las observaciones formuladas por la ciudadanía respecto de los instrumentos de evaluación ambiental, sometidos a este procedimiento.

4. La autoridad ambiental debe periódicamente publicar y poner a disposición de la ciudadanía y actores institucionales los resultados del monitoreo ambiental en el cantón, lo cual ayudaría a llevar una permanente veeduría social sobre los procesos de gestión ambiental tanto públicos como de la empresa privada.

5. El área de desarrollo social del Gobierno Autónomo Descentralizado Municipal del cantón Cuenca, debe trabajar en el fortalecimiento de las organizaciones de base, para lograr alcanzar un empoderamiento ciudadano respecto del ambiente y su relación con los servicios, la infraestructura, la producción y en definitiva con el desarrollo. 


\section{BIBLIOGRAFÍA JURÍDICA}

> Arenas, José Antonio. Diccionario Técnico y Jurídico del Medio Ambiente, Mc Graw Hill, 2000, Madrid, España.

> Constitución de la República del Ecuador. EDIJUR 2008, Quito, Ecuador.

$>$ Decreto Ejecutivo No. 1040. R. O. No. 332, 2008, Quito, Ecuador.

$>$ Hauriou, Maurice. Derecho Administrativo y Derecho Público. Jurídica 2007, México.

> Hidalgo, R., Crespo, R., Calvache, R. Manual de Capacitación en Derecho Ambiental y Código de Procedimiento Penal para Fiscales del Ministerio Público. CEDA, 2004, Quito, Ecuador.

$>$ Ley de Gestión Ambiental. R. O. 245, 1999, Quito, Ecuador.

> Ordenanza de Aplicación del Subsistema de Evaluación de Impacto Ambiental, dentro de la Jurisdicción del cantón Cuenca. I. Concejo Cantonal de Cuenca. 2009, Cuenca, Ecuador.

$>$ Pérez Camacho, Efraín. Derecho Ambiental y de los recursos naturales, Edino, 1995, Guayaquil, Ecuador.

$>$ Santander Mejía, Enrique. Instituciones del Derecho Ambiental. Ecoe Ediciones, 2002, Bogotá, Colombia.

> Serrano, Vladimir. Ecología y Derecho. FESO, 1998, Quito, Ecuador. 
> Texto Unificado de Legislación Ambiental Secundaria del Ministerio del Ambiente. R. O. 2, 2003, Quito, Ecuador.

\section{BIBLIOGRAFÍA EXTRAJURÍDICA}

> Albán, Ma., Barragán, D., Bedón, R., Crespo, R., Echeverría, H., Hidalgo, Ma., Muñoz, G., y Suarez, S. Ecuador Ambiental 1996-2011 Un recorrido propositivo. CEDA 2011, Quito, Ecuador.

> Bucheli, F., Coronel, I., Idrovo, E., Espinoza, A. Manual de Gestión Ambiental. MAE/PATRA/CGA/l. Municipio de Cuenca 2000. Cuenca, Ecuador.

> Negret, Rafael. De la protesta ecológica a la propuesta política, en el sendero del desarrollo sostenible. ESKELETRA Quito 1999.

\section{SITIOS WEB}

$>$ www.ambiente.gob.ec

> www.asambleanacional.gob.ec

$>$ www.ceda.org.ec

$>$ www.cuencacga.gov.ec 